\title{
Research as a service offering of knowledge management firms in the fourth industrial revolution
}

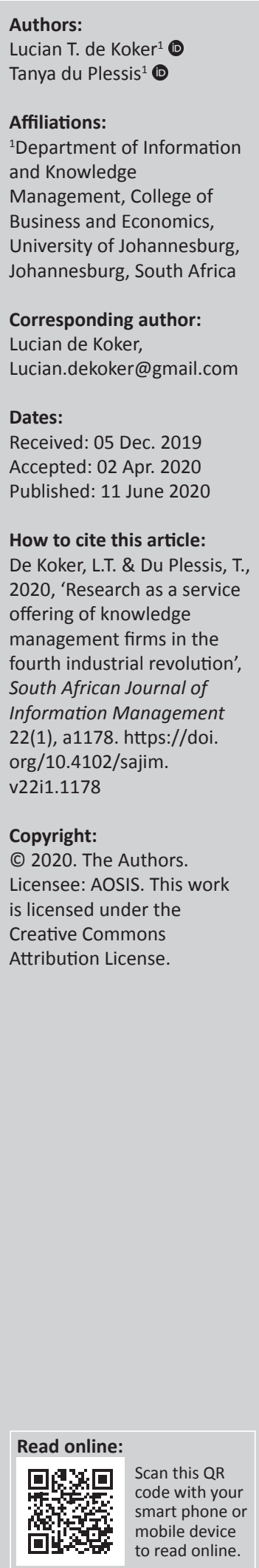

Background: The fourth industrial revolution (4IR) is primarily based on innovative new technologies, such as artificial intelligence, robotics, and the Internet of Things, which is generally considered as a driving force behind recent global changes. This revolution is reshaping economies, the global landscape and business ecosystems. The 4IR is disrupting the status quo of traditional business operations.

Objective: The research objective was to determine how a newly-developed information and knowledge management framework can be used as an enabler for knowledge management (KM) firms to successfully conduct business in the 4IR, further establishing if new innovative services are required for KM firms in the 4IR.

Methods: Qualitative research methodology was used to select business cases, and critical case sampling was used for the selection of interviewees. Structured content analysis was conducted on the business cases, and in-depth face-to-face interviews were conducted with the interviewees.

Results: The result was the development of an information and knowledge management framework that can be used as a new 4IR enabler by KM firms. The research elaborates on a new service offering that was developed specifically for the KM firm, namely Research as a Service.

Conclusion: Knowledge management firms need to adapt their existing business frameworks, business models and commercialisation lifecycles, to ensure that the business is prepared for successful business operations in the 4IR.

Keywords: fourth industrial revolution; information and knowledge management framework; knowledge management firm; Research as a Service; business models.

\section{Introduction}

The fourth industrial revolution (4IR) was announced and recognised in Germany in the year 2011. It would be beneficial for professional business firms, especially entrepreneurs and small businesses, to proactively understand what is required of a business to remain competitive in the 4IR. Over the past couple of years, a rise in the growth and development of technologies of the 4IR has been seen, specifically, artificial intelligence (AI), the Internet of Things, and robotics. Various economies and organisations have realised the need for upskilling for the 4IR and have started to invest in such efforts. Schwab $(2016 a, 2016 b)$, notes that the 4IR is primarily characterised by a range of new technologies, such as AI, the Internet of Things and robotics, through which the interconnectedness of physical, digital and biological worlds will be seen, with a direct impact on all economies, businesses and industries. With the 4IR bringing the colossal change as depicted by Schwab (2016a), it is imperative that new frameworks are adopted for conducting business.

Professional business consulting firms increasingly include information and knowledge management (IKM) in their business consultation services:

Information and knowledge management is defined as the simultaneous management of numerous processes associated with both information (information management) and knowledge (knowledge management), to generate and contribute to the overall competitiveness of an organisation. (De Koker 2019:xiii)

An IKM framework for knowledge management (KM) firms is required, to improve the likelihood of successful business in the 4IR.

With the advent of the 4IR and all the changes that are associated with the 4IR, businesses will need to upskill, change and prepare for the 4IR in order to be competitive (Forbes 2018; Matskevich 2018). 
This study developed an IKM framework specifically for $\mathrm{KM}$ firms to be utilised by them as a guideline for successful business operations in the 4IR. Furthermore, a new service offering was developed, namely, Research as a Service (RaaS), implemented through the Research Methodology Value Proposition $\left(\mathrm{RM}^{\mathrm{VP}}\right)$. As the definition of IKM provided above states, the IKM framework was developed with the stance that business processes associated with both information (information management) and knowledge (knowledge management), should be included and managed in the IKM framework.

The objective for this research was:

- to determine how a newly-developed information and knowledge management framework can be used as an enabler for knowledge management firms to successfully conduct business in the 4IR.

- to determine if new innovative services are required for KM firms in the 4IR.

In order to adhere to the objective of the study, a literature review of information and knowledge management elements was done, as can be found in the next section.

\section{Literature review}

The IKM framework used as an enabler for KM firms to conduct business in the 4IR was a newly-developed tool, and was based on five IKM elements. The five IKM elements are pivotal in the IKM framework, under which 25 criteria exist. The five IKM elements that will be discussed here are: (1) components of a commercialisation lifecycle, (2) components of the business model canvas, (3) features of digital business transformation, (4) features of the 4IR, and (5) principles of strategic information management.

\section{Components of a commercialisation lifecycle}

Razak, Murray and Roberts (2014:262) explain that 'commercialisation success is about converting ideas and new innovations into new marketable products'. Many researchers view commercialisation as a process, with innovation being introduced into the market. Innovation can be a product and or a service (Bers et al. 2008; Cannatelli et al. 2017; Razak et al. 2014). The components of the commercialisation lifecycle (CLC) made up six of the 25 criteria in the IKM framework, namely: (1) idea generation, (2) research, (3) concept development and testing, (4) analysis, (5) product or service development, market testing and marketing, and (6) commercialisation stage.

Dehghani (2015) explains that for any business to turn a service into a profit, the service needs to undergo commercialisation. In order to create economic value it is necessary to 'build a successful profitable business', which means 'creative ideas should be commercialized' (Dehghani 2015:193). For every business, its CLC would be unique. Different businesses may share elements of CLCs but are ultimately different in stages. There exist no specific
CLC suitable for all organisations and contexts (Ismail, Nor \& Sidek 2015:288), therefore a unique CLC is adapted for the IKM framework.

Idea generation is crucial for innovation, which is the starting point and first stage in the CLC (Dehghani 2015:196; Foss et al. 2013:28). Innovation is not a specific stage in the CLC; however, innovation is important for idea generation and idea generation is important for innovation (Ojasalo \& Ojasalo 2018a, 2018b). Furthermore, Gurtner and Reinhardt (2016:34) believe that 'idea generation is the most important part of the innovation process because it is the starting point'.

Research is done to understand the feasibility, eligibility and appetite for the idea (to become a service) in any given market (Bansi 2016:357; Khumalo \& Du Plessis 2017:198; Ojasalo \& Ojasalo 2018a). Thorough research can further reveal if the market is ready for such a service and determine if any competitors operate in the market, if any at all (Ojasalo \& Ojasalo 2018b). According to Moore (2009:28), 'once a new idea or solution to a problem is recognized, that invention's viability must be researched and protected either with patents or secrecy'.

Depending on the type of business, concept development and testing differs from business to business and economy to economy (Drucker 1992, 1993; Kotter 2012; Moore 2009; Watson 2017). During the third stage of the CLC, concepts are developed and tested to determine which concept has the potential to move forward in the CLC.

In the analysis stage of the CLC, many ideas have been looked at, with only a few ideas remaining, as all the ideas have gone through a filtering process (Bansi 2016). The analysis stage forecasts the market demand, costs (production) involved, and the sales and profits (Ojasalo \& Ojasalo 2018a). Analysed results will provide valuable intelligence on what the target markets expect (Illbury 2012; Jordan 2010).

During the product or service development, market testing and marketing stage, the actual product or service is developed as a prototype (Bansi 2016; Moore 2009; Razak et al. 2014). The prototype is offered to a group of clients, who then scrutinise the offering. Product or service development, market testing and marketing allow for improvement of the prototype, basically having the prototype in an iterative cycle in this stage, until the prototype is transformed into the actual product or service (Furr \& Dyer 2014; Watson 2017).

Once the development of the product or service is complete, the product or service is sold at a price to the target market, as was established in the analysis stage. Innovation can be commercialised successfully to the market, leading to improved income streams (Latif, Abdullah \& Jan 2016:94). At this stage, the product or service is sold, and a profit is generated. The process of commercialisation is a cycle whereby a given input passes through a series of stages to reach a specific output and in every stage some value is added to it' (Dehghani 2015:193). 


\section{Components of the business model canvas}

'A business model describes the rationale of how an organization creates, delivers, and captures value' (Ojasalo \& Ojasalo 2018b:72; Osterwalder \& Pigneur 2010:14). Nine building blocks are found in the business model canvas (BMC), namely: (1) customer segments, (2) value propositions, (3) channels, (4) customer relationships, (5) revenue streams, (6) key resources, (7) key activities, (8) key partners, and (9) cost structure. These building blocks made up nine of the 25 criteria in the IKM framework.

'The customer segments building block defines the different groups of people or organizations an enterprise aims to reach and serve' (Ojasalo \& Ojasalo 2018b:72; Osterwalder \& Pigneur 2010:20). The customer segments building blocks for the KM firm include Government Institutions, Private Companies, Small Businesses and Entrepreneurs. The KM firm focuses on the above as its core customers, with a view that a beneficial and mutual relationship can be maintained. Customers are core to the KM firm, which results in profitability. 'In order to better satisfy customers', the KM firm will group the customers into 'distinct segments with common needs, common behaviors, or other attributes' (Osterwalder \& Pigneur 2010:20). The KM firm has to ensure that the business model is designed around 'a strong understanding of specific customer needs' (Osterwalder \& Pigneur 2010:20).

'The value propositions building block describes the bundle of products and services that create value for a specific Customer Segment' (Ojasalo \& Ojasalo 2018b:73; Osterwalder \& Pigneur 2010:22). The value proposition sets the KM firm apart from its competitors. The value proposition offers something unique to the customer; it solves a customer's problem and provides a product or service based on the customer's need.

'The channels building block describes how a company communicates with and reaches its customer segments to deliver a Value Proposition' (Ojasalo \& Ojasalo 2018b:72; Osterwalder \& Pigneur 2010:26). The channels for the KM firm include the KM firm's Website, Social Media, Direct Selling processes, and Referrals from the KM firm's network. Channels are crucial to the KM firm, as they are the point(s) where the business interacts with the customer or potential customer.

'The customer relationships building block describes the types of relationships a company establishes with specific customer segments' (Ojasalo \& Ojasalo 2018b:73; Osterwalder \& Pigneur 2010:28). The KM firm will ensure customer relationships are maintained through Client Relationship Management, dependent on project timelines (e.g. weekly, monthly). This can be face-to-face, telephonic, or through automated engagement.

'The revenue streams building block represents the cash a company generates from each customer segment (costs must be subtracted from revenues to create earnings)' (Ojasalo \&
Ojasalo 2018b:73; Osterwalder \& Pigneur 2010:30). Every project determines the revenue stream, based on the size and duration of a project. Resources working on a project will also have a determining factor on the revenue streams. Possible Revenue Streams for the KM firm will be determined based on the resources required for a specific project.

'The key resources building block describes the most important assets required to make a business model work' (Ojasalo \& Ojasalo 2018b:73; Osterwalder \& Pigneur 2010:34). Any business requires resources to function optimally; specifically, for the KM firm, the Key Resources are Human Resources (Researchers) and Physical Assets (computers, data services, transportation). Researchers are insourced, who will be the primary resource for the KM firm.

'The key activities building block describes the most important things a company must do to make its business model work' (Ojasalo \& Ojasalo 2018b:73; Osterwalder \& Pigneur 2010:36). The key activity for the KM firm is the RaaS.

'The key partners building block describes the network of suppliers and partners that make the business model work' (Ojasalo \& Ojasalo 2018b:73; Osterwalder \& Pigneur 2010:38). The KM firm's key partners include Universities (Academic Researchers), Research Institutions, Entrepreneurs, and Small Businesses.

'The cost structure describes all costs incurred to operate a business' (Ojasalo \& Ojasalo 2018b:73; Osterwalder \& Pigneur 2010:40). The KM firm is initially funded by the founder, however additional funding is required to expand the business operations. Second round funding is required, in order to expand on Human Resources, and improving the RaaS and the RMVP (Value Proposition to render services).

\section{Features of digital business transformation}

According to Schwertner (2017:388), the use of new technologies for the development of new business models, new business processes, new workflows, new technologies, new software, new systems and new services leading to the improvement of business operations and efficiency, and further resulting in greater profit generation for the business, can be defined as digital business transformation (DBT). The features of DBT made up four of the 25 criteria in the IKM framework, namely: (1) innovation is key to the organisation, (2) big data are embedded in the organisation, (3) business process automation is found in the organisation, and (4) information security is key in the organisation.

According to Perkin and Abraham (2017):

Heightened pace and progression through broad and proficient adoption and application of digital-native processes including design thinking, agile and lean, continuous experimentation and a culture that supports constant testing and learning, coupled with an exhaustive, customer-centric innovation process that enables rapid origination, validation and commercialization of ideas $[\ldots]$ (p. 55) 
... relates to agility leading to innovation as key in the organisation. The KM firm ensures that innovation is embedded in the RaaS process. The RaaS process should, in turn, generate innovative results for the customer. The RMVP is thus achieved for the customer, ensuring that the customer is competitive in the $4 \mathrm{IR}$.

In the DBT process, enormous amounts of data are produced, constituting big data (Geng 2017:13):

Data-driven decision-making is essential in the agile business. Data is central to the flow of knowledge into and within a business, to governance processes, performance optimization and customer experience delivery. (Perkin \& Abraham 2017:158)

Many organisations struggle with big data, in that the organisation is unable to make sense thereof (Marr 2017:8-27). It is therefore important for the KM firm to ensure that it is able to provide RaaS in such a manner that it allows for the customer to make sense of the big data in the organisation (customer). This leads to the customer leveraging the $4 \mathrm{IR}$, as big data is the backbone for technologies to be effective in the 4IR.

According to Perkin and Abraham (2017:161), 'business process automation, to communication and notification systems, customer service interaction, marketing automation and lead management, workflow automation can bring powerful efficiency benefits' to the organisation. Business process automation, however, does not mean that every process will be automated, as human intervention will be required when, for instance, formulating a strategy (Nakamura \& Zeira 2018). With regard to the KM firm, RaaS should be offered in a manner which will allow for the customer to automate certain processes but be able to keep the human aspect embedded for certain processes and function, such as strategy development:

In response to privacy and data security laws [...] businesses have expanded their protections to cover personal information about individuals. Partitioning off this information, responsible organizations have invested heavily in protecting the privacy and security of these data, and ensuring compliance with applicable legal requirements. Bruening et al. (2008:2)

With this in mind, Bruening et al. (2008:2) explain that 'a company's information assets must be managed in accordance with laws that are far broader than those regulating only privacy and information security'. Information security is crucial for any organisation operating in the 4IR and specifically for the KM firm; when offering RaaS or any other service to customers, the KM firm will have to ensure that information security is addressed according to appropriate laws and legislation geared for the 4IR.

\section{Features of the fourth industrial revolution}

The founder and executive chairman of the World Economic Forum, Klaus Schwab, explains in his book that humankind, like never before, is engaged in a revolution that will change the everyday lives of humanity (Schwab 2016a:1), and this revolution is known as the 4IR (Schwab 2016a:1). In some instances, this is also referred to as Industry 4.0 (Magruk 2016:275), with existing Industry 4.0 literature depicting that $\mathrm{KM}$ and decision-making strategies are crucial factors for organisations (Abubakar, Elrehailb \& Alatailat 2017), and that the 4IR will bring colossal change to the world, in various economies, businesses and private life, which will happen at a much faster rate than ever anticipated or experienced in history (Schwab 2016a:1). The features of the 4IR made up three of the 25 criteria in the IKM framework, namely (1) AI, (2) robotics, and (3) the Internet of Things.

Makridakis (2018:18), explains that AI will have the most profound effect on firms and employment in the immediate future, 'for it is in the world of business, manufacturing, commerce, and government that AI will likely have the most profound effects on our lives, for good and ill' (Makridakis 2018:18). Skilton (2017) explains that AI technologies will provide new opportunities and a competitive advantage in the market for the business. The KM firm needs to take advantage of these new AI technologies, allowing for greater service delivery to customers:

The Internet of Things is a system consisting of networks of sensors, actuators, and smart objects whose purpose is to interconnect 'all' things, including every day and industrial objects, in such a way as to make them intelligent, programmable, and more capable of interacting with humans and each other. (Geng 2017:7)

In the $4 \mathrm{IR}$, the KM firm needs to take advantage of the fact that everything is connected through the Internet of Things. This allows for collection of valuable data that can be used to make predictions about customers and future scenarios referred to as predictive analytics:

Robotics is the industry related to the engineering, construction and operation of robots - a broad and diverse field related to many commercial industries and consumer uses. The field of robotics generally involves looking at how any physical constructed technology system can perform a task or play a role in any interface or new technology. (Technopedia 2018; https://www.techopedia.com/definition/32836/robotics)

Businesses and economies are being disrupted by new technologies in the 4IR, to an extent where the loss of jobs as a result of robotics, is becoming a concern. Businesses and economies will have to adapt current business models, providing skills development to those who are in the path of jobs being lost due to robotics.

\section{Principles of strategic information management}

Strategic information management (SIM) is defined as a situation in which 'information and related resources [...] are used or utilized by an organization (profit or non-profit) to support, implement or achieve strategic position in order to gain competitive advantage/strategic advantage' (Hussin, Hashim \& Yu 2018:292). Strategic information management focuses on the overall strategic management of all the confidential and non-confidential information (data, information, tacit and explicit knowledge, wisdom 
and intelligence) in any form (physical and electronic) in a business. In the context of the IKM framework, the IKM element SIM is used, with the view that SIM is crucial for any organisation to be competitive. Based on the assertions of Huggett, Hoos and Rensink (2007), Mutula and Wamukoya (2007), Davenport and Patil (2012), Zulu et al. (2012), and Bwalya and Saul (2014), four timeless principles for SIM have been identified for this study, namely: (1) information is a key asset to the organisation, (2) information is integrated in the overall strategy of the organisation, (3) information is managed strategically in the organisation, and (4) information is crucial to the success of the organisation

These four timeless principles made up the remaining four of the 25 criteria in the IKM framework.

Many researchers agree that the first principle, 'information is a key asset for any organisation', is an important factor adding to competitive advantage (Bruening et al. 2008; Galliers \& Leidner 2003; ed. Galliers \& Leidner 2014; ed. Galliers \& Stein 2018; Hussin et al. 2018). Information is a key asset and should be managed strategically. In terms of the KM firm offering services to its customers, the KM firm needs to ensure that information is managed strategically as an information asset that is key to the customer's competitive advantage in the 4IR.

The second SIM principal states that 'information is integrated in the overall strategy of the organisation', and according to Hussin et al. (2018:293), SIM begins with mastering and understanding how to think strategically. During the SIM process, a strategic plan is developed, implemented and assessed for effectiveness. As a combination of strategic management and information management, SIM is crucial in order for an organisation to achieve its organisational objectives. With regard to the KM firm's service offering, it should offer RaaS strategically to customers, making sure that information is integrated in the overall strategy of the organisation.

The third SIM principle, 'information is managed strategically in the organisation', resonates with the declarations of Galliers and Leidner (2003:21), Dearstyne (2004:33), Bruening et al. (2008:3), and Hussin et al. (2018:293). Information should be managed strategically, taking into account that people and technology are key in the strategic management of information. Bruening et al. (2008), further states that:

$[M]$ anaging information strategically not only mitigates risk, it shapes decisions about data to assure that this critical resource is available to the appropriate personnel when needed. It fosters sound investment in data and data systems that meet the diverse needs of the business. (p. 3)

With the support of technology, SIM adds to the overall competitiveness of an organisation through the alignment of organisational objectives with SIM objectives.
The fourth and last SIM principle, 'information is crucial to the success of the organisation' is supported by Galliers and Leidner (2003:19), Bruening et al. (2008:1), Iuga and Kifor (2014:32), and Hussin et al. (2018:293). They agree that the fourth principle leads to a competitive advantage for an organisation. Information is used strategically, aligned to the objectives of the organisation, giving the organisation a competitive advantage over competitors. The KM firm needs to ensure that when offering services to customers, information managed strategically should be instilled in the business models of customers.

\section{Service offering - Research as a Service}

Research in the CLC leads to the design of the service offering (Watson 2017). The service offering is referred to as RaaS. The primary service the KM firm offers is Research, referred to as RaaS, constituting a major component of the service offering of the KM firm. The RaaS offered by the KM firm is the competitive edge of the business. The actual value proposition is known as the Research Methodology Value Proposition ( $\left.\mathrm{RM}^{\mathrm{VP}}\right)$, not to be confused with the Research Methodology of the study. The RM ${ }^{\mathrm{VP}}$ is the method or process in which RaaS is conducted or offered, adding the value proposition perspective to the service offering.

\section{Research methodology}

According to Saunders, ' $[r]$ esearch is value bound, the researcher is part of what is being researched, cannot be separated and so will be subjective' (2009:119). This research study had the researcher embedded in every step of the research process, so interpretivism was selected for the study. The inductive research approach was chosen for the research. Saunders, Lewis and Thornhill (2012:165) explain that the collection of data to explore a 'specific phenomenon, identify themes and or explain patterns', refers to inductive reasoning, which is best suited for research where limited theory exists for what is being researched, leading to the development of theory through the analysis of data collected. Qualitative research was conducted to determine how the development of a new IKM framework can be used as an enabler for a KM firm to conduct business in the 4IR. The multi-method qualitative research method was used for this study. This was deemed appropriate, as two data collection techniques were used. The data collection techniques used were content analysis of 101 strategic information management business case studies (BCSs), and an interview process including four participants. The selection of participants for the interview process derived from the concept of content analysis. Methodological choices in terms of critical case sampling were selected under purposive sampling techniques, with the selection of BCSs based on the five IKM elements and 25 criteria used under the Nominal Ranking Technique, which was used to rank the BCSs based on their relevance. From the 101 BCSs, the top four were selected and used for the next phase in 
the research. The next phase was the interview process, during which three out of the four participants from the four BCSs were interviewed, in individual in-depth face-to-face interviews. The fourth participant was used in the triangulation process, to test the findings from the interviews and the content analysis.

Purposive sampling was best suited since it allowed the research to make use of critical case sampling, selecting critical cases on the basis of importance, in order to understand each case critically so that logical generalisations could be made (Saunders, Lewis \& Thornhill 2009:240). The Data Analysis Spiral method which, according to Creswell (2013:182), is not a set process, but is rather customised for the specific research, was best suited for the study. The Data Analysis Spiral was specifically used to ensure the reliability and validity of the research, through continuous triangulation.

\section{Ethical consideration}

Ethical clearance was obtained from the Faculty of Management Faculty Ethics Committee, University of Johannesburg in 2016. Reference number: FOM2016-IKMNov2016_4.

\section{Results and discussion}

The newly-developed IKM framework is offered in the form of a service offering, namely RaaS. Research as a Service was coined as the service offering in the study, together with the methodology through which the RaaS is offered. The methodology is the value proposition, coined as the $\mathrm{RM}^{\mathrm{VP}}$. Figure 1 illustrates how the five IKM elements and 25 criteria are housed in the IKM framework, each indicated with a different colour. The first element is the CLC, shown in red. The second element is the BMC (orange), the third element is DBT (green), the fourth element is the 4IR (purple), and the fifth element is SIM (blue).

The IKM framework is illustrated below in Figure 1.

The outer layer of the IKM framework shows the RaaS in the KM firm, which is the service offered by the KM firm. Within the RaaS in the KM firm, the RM ${ }^{\mathrm{VP}}$ (the value added to the RaaS) is found, namely, a method or process in which RaaS is conducted or offered to clients. The five IKM elements and 25 criteria are embedded in the RaaS. The KM firm renders RaaS to a client, making use of the IKM framework as a guideline for implementation in the

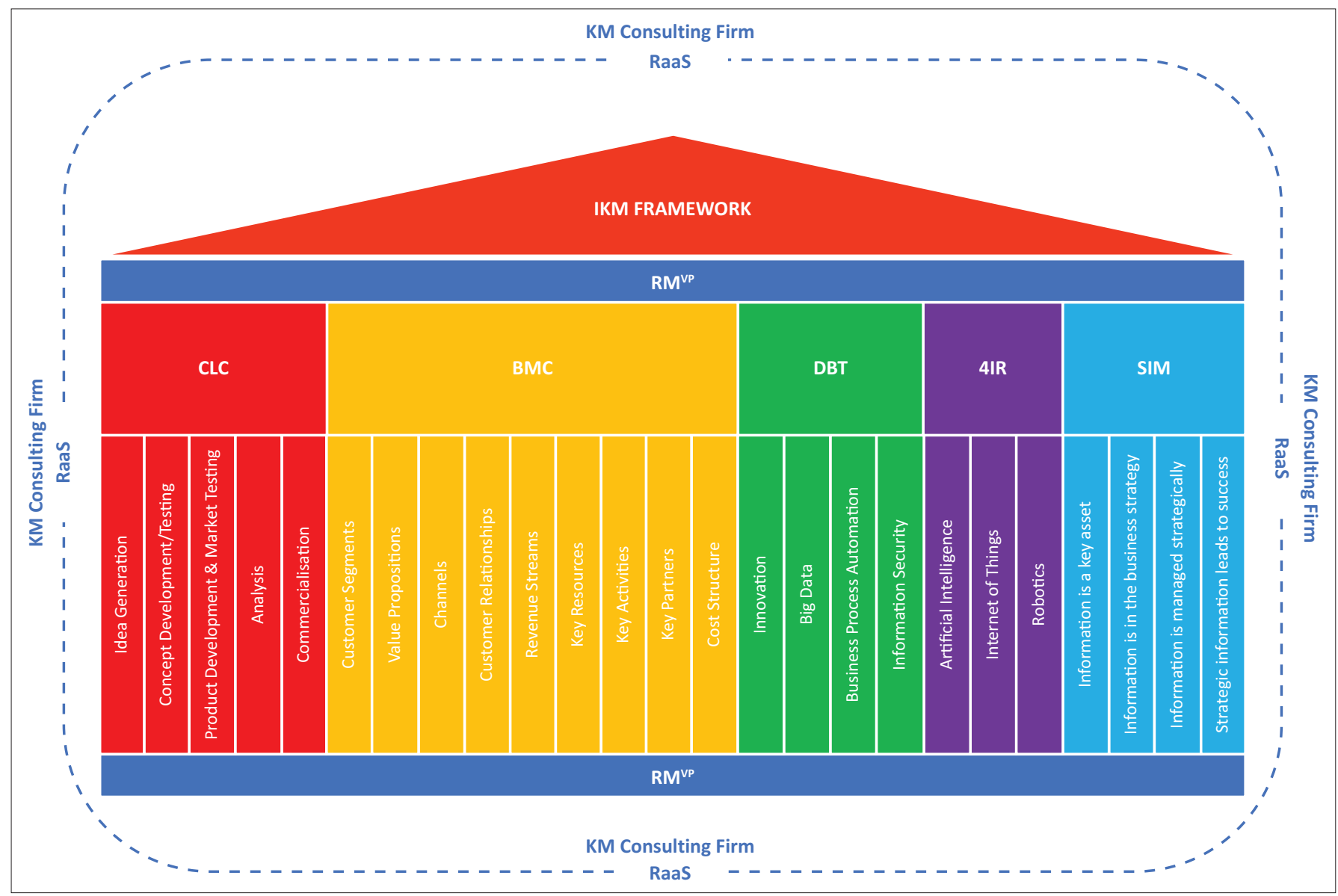

Source: De Koker, L.T., 2019, 'The commercialisation lifecycle of a knowledge management consulting firm in the fourth industrial revolution', Master's dissertation, University of Johannesburg, Auckland Park; and De Koker, L.T. \& Du Plessis, T., 2019, 'Development of a framework for a knowledge management firm in the fourth industrial revolution', in M. Twum-Darko (ed.), Pragmatic business solutions by Africa for Africa: 5th International Conference on Business and Management Dynamics 2019 proceedings, AMHI, Cape Peninsula University of Technology in collaboration with University of Namibia Business School, Swakopmund, September 02-04, 2019, pp. 109-121

IKM, Information and knowledge management; CLC, components of a commercialisation lifecycle; BMC, business model canvas; DBT, digital business transformation; 4IR, fourth industrial revolution; SIM, strategic information management; RaaS, Research as a Service; RM ${ }^{\mathrm{vp}}$, Research Methodology Value Proposition.

FIGURE 1: Information and knowledge management framework. 
client's business, as relevant for the 4IR. The RM ${ }^{\mathrm{VP}}$ is added to the RaaS through the five IKM elements and 25 criteria. A utopian situation will be achieved when all five IKM elements and 25 criteria are present within the business of the client. In the event where there are only certain IKM elements and criteria of the IKM framework in a client's business, the IKM framework should be used to guide the implementation of the missing IKM elements and criteria.

The IKM framework does not follow a specific order in which the five IKM elements and 25 criteria should be implemented in a business. Businesses differ; therefore implementation will depend on the needs of the business at that point in time. Based on the IKM framework, the elements are CLC, BMC, DBT, 4IR and SIM, and will be deliberated on in that order.

Evidence showed that the IKM framework will be beneficial to a KM firm and to clients of a KM firm. The evidence further showed that the IKM framework will add a unique value proposition $\left(\mathrm{RM}^{\mathrm{VP}}\right)$ to the service offering (RaaS) of a KM firm.

The IKM framework can be implemented systematically, differently for each client business, ensuring that the specific business need of the client is met. There is no prescribed order in which the IKM framework is implemented, however, when all five IKM elements and 25 criteria are implemented in the client's business, competitive advantage will be achieved. In order for a KM firm to achieve competitiveness in the 4IR, it is recommended that the IKM framework should be used as indicated. The application of the IKM framework could be beneficial to other types of businesses as well, keeping in mind that the implementation and application of the IKM framework will differ from business to business, based on the needs of the business.

\section{Conclusion}

The newly-developed IKM framework as an enabler provides KM firms with a guideline and business tool that can be utilised through systematic implementation and application, and which will lead to business competitiveness and success in the $4 \mathrm{IR}$.

To grow the IKM framework to extensively include and cater for all business types, research can be done to determine if more than five IKM elements and 25 criteria should be included. Further, on the point of inclusion of other IKM elements and criteria, research can be done to determine if the 4IR element and criteria should be broadened.

Future research can also be done to determine if the proposed IKM framework could be linked to other existing business frameworks and business models. As the world changes and businesses change and grow, CLCs, BMCs, business frameworks and business models need to change and adapt to the changing environment. New CLCs,
BMCs, business frameworks and business models will continually be required, therefore research should be done to determine how these CLCs, BMCs, business frameworks and business models will change and how these CLCs, BMCs, business frameworks and business models will adapt beyond the 4 IR.

The RaaS as service offering and $\mathrm{RM}^{\mathrm{VP}}$ as method of implementing the RaaS, were developed in conjunction with the IKM framework, together offering a unique guideline to a KM firm for competitive business operations in the $4 \mathrm{IR}$.

\section{Acknowledgements Competing interests}

The authors declare that they have no financial or personal relationships that may have inappropriately influenced them in writing this article.

\section{Authors' contributions}

L.T.d.K. conducted the overall Master's study whilst registered as a student at the University of Johannesburg. T.d.P. supervised the study and contributed to the writing of the article.

\section{Funding information}

This research received no specific grant from any funding agency in the public, commercial or not-for-profit sectors.

\section{Data availability statement}

The data that support the findings of this study are available from the corresponding author, L.T.d.K., upon reasonable request. The IKM framework (Figure 1), developed by the researcher (L.T.d.K.), is the intellectual property of said researcher.

\section{Disclaimer}

The views and opinions expressed in this article are those of the authors and do not necessarily reflect the official policy or position of any affiliated agency of the authors.

\section{References}

Abubakar, M.A., Elrehailb, H. \& Alatailat, M.A., 2017, 'Knowledge management, decision-making style and organizational performance', Journal of Innovation \& Knowledge 4(2), 104-114. https://doi.org/10.1016/j.jik.2017.07.003

Bansi, R., 2016, 'Commercialization of university innovation in South Africa', DTech Public Management dissertation, Faculty of Management, Durban University of Technology, Durban.

Bers, J.A., Dismukes, J.P., Miller, L.K. \& Dubrovensky, A., 2008, 'Accelerated radical innovation: Theory and application', Technological Forecasting \& Social Change 76(2009), 165-177. https://doi.org/10.1016/j.techfore.2008.08.013

Bruening, P.J, Sotto, L.J, Abrams, M.E. \& Cate, F.H., 2008, 'Strategic information management', Privacy and Security Law Report 7(36), 1-3.

Bwalya, K.J. \& Saul, Z.F.C., 2014, 'Unleashing the conceptual value of information management for organisational competitiveness: Semantic understandings', in K.J. Bwalya, N.M. Mnjama \& P.M.M. Sebina (eds.), Concepts and advances in Information and Knowledge Management: Studies from developing and emerging
Int. economies, Chandos Publishing, Amsterdam; pp. 111-127. 
Cannatelli, B., Smith, B., Giudici, A., Jones, J. \& Conger, M., 2017, 'An expanded mode of distributed leadership in organizational knowledge creation', Long Range Planning 50(2017), 582-602. https://doi.org/10.1016/j.Irp.2016.10.002

Creswell, J.W., 2013, Qualitative inquiry and research design: Choosing among five approaches, 3rd edn., Sage Publications, Thousand Oaks, CA.

Davenport, T.H. \& Patil, D.J., 2012, 'Data scientist', Harvard Business Review 90(5), 70-76.

Dearstyne, B., 2004, 'Strategic information management: Continuing need, continuing opportunities', The Information Management Journal 38(2), 28-36.

Dehghani, T., 2015, 'Technology commercialization: From generating ideas to creating economic value', International Journal of Organizational Leadership 4(2015), 192-199. https://doi.org/10.33844/ijol.2015.60449

De Koker, L.T., 2019, 'The commercialisation lifecycle of a knowledge management consulting firm in the fourth industrial revolution', Master's dissertation, University of Johannesburg, Auckland Park.

De Koker, L.T. \& Du Plessis, T., 2019, 'Development of a framework for a knowledge management firm in the fourth industrial revolution', in M. Twum-Darko (ed.), Pragmatic business solutions by Africa for Africa: 5 th International Conference on Business and Management Dynamics 2019 proceedings, AMHI, Cape Peninsula University of Technology in collaboration with University of Namibia Business School, Swakopmund, September 02-04, 2019, pp. 109-121.

Drucker, P.F., 1992, 'The new society of organisations', Harvard Business Review 70(5), 95-104.

Drucker, P.F., 1993, Post-capitalist society, Butterworth Heinemann, Oxford.

Forbes, 2018, How is artificial intelligence changing the business landscape?, viewed 22 August 2018, from https://www.forbes.com/sites/quora/2018/07/31/how-isartificial-intelligence-changing-the-business-landscape/\#4553189b75f4.

Foss, N., Pedersen, T., Pyndt, J. \& Schiltz, M., 2013, Innovation organization \& management: New sources of competitive advantage, Cambridge University Press, Copenhagen.

Furr, N. \& Dyer, J., 2014, 'Choose the right innovation method at the right time', Harvard Business Review 12, viewed 22 August 2018, from https://hbr org/2014/12/choose-the-right-innovation-method-at-the-right-time.

Galliers, R.D. \& Leidner, D.E., 2003, Strategic information management: Challenges and strategies in managing information systems, 2nd edn., Butterworthand strategies in

Galliers, R.D. \& Leidner, D.E. (eds.), 2014, Strategic information management: Challenges and strategies in managing information systems, 4th edn,. Routledge, Oxford.

Galliers, R.D. \& Stein, D.E. (eds.), 2018, The Routledge companion to management information systems, Routledge, Oxford.

Geng, H., 2017, Internet of things and data analytics handbook, John Wiley \& Sons, Inc., New Jersey, NJ.

Gurtner, S. \& Reinhardt, R., 2016, 'Ambidextrous idea generation: Antecedents and outcomes', Product Development \& Management Association 33(S1), 34-54. https://doi.org/10.1111/jpim.12353

Huggett, M., Hoos, H. \& Rensink, R., 2007, 'Cognitive principles for information management: The principles of mnemonic associative knowledge (P-MAK)', Mind \& Machines 17, 451-485. https://doi.org/10.1007/s11023-007-9080-4

Hussin, N., Hashim, H. \& Yu, H., 2018, 'Strategic information management (SIM) in Malaysian organizations: An investigation of its antecedent', International Journa of Academic Research in Progressive Education and Development 7(3), 291-304, viewed 19 November 2018, from http://hrmars.com/hrmars_papers/Strategic Information Management_(SIM)_In_Malaysian_Organizations_An Investigation_of_its_Antecedent11.pdf.

Illbury, C., 2012, Welcome to the age of the fox thinking the future, Human \& Rousseau, Cape Town.

Ismail, N., Nor, M.J.M. \& Sidek, S., 2015, 'A framework for a successful research products commercialisation: A case of Malaysian academic researchers', Procedia
- Social and Behavioral Sciences 195, 283-292, viewed 21 August 2018, from - Social and Behavioral

luga, V. \& Kifor, C.V., 2014, 'Information and knowledge management and their interrelationship within lean organizations', Bulletin Scientific 1(37), 31-38.

Jordan, J.F., 2010, Innovation, commercialization, and the successful start-up, Heinz College, Carnegie.

Khumalo, S. \& Du Plessis, T., 2017, 'Responsiveness of a South African university to the country's agenda for entrepreneurial universities', in Proceedings of the Africa Research Group 5th International Conference: Managing Organisations in Africa, University Of Mauritius in collaboration with University of Nottingham, Belle Mare, Mauritius, August 29-31, 2017.
Kotter, J.P., 2012, 'How the most innovative companies capitalize on today's rapid-fire strategic challenges and still make their numbers: Accelerate!', Harvard Business Review 97, 44-58.

Latif, N.S.A., Abdullah, A. \& Jan, N.M., 2016, 'A pilot study of entrepreneurial orientation towards commercialization of university research products', Procedia Economics and Finance 37, 93-99, viewed 25 July 2018, from www. Procedia Economics
sciencedirect.com.

Magruk, A., 2016, 'Uncertainty in the sphere of the Industry 4.0 - Potential areas to research', Business, Management and Education 14(2), 275-291. https://doi. research', Business, Managem
org/10.3846/bme.2016.332

Makridakis, S., 2018, 'Forecasting the impact of artificial intelligence: Part 3 of 4: The potential effects of Al on businesses, manufacturing and commerce', Foresight, viewed from https://foresight.forecasters.org.

Marr, B., 2017, Big data in practice, John Wiley \& Sons, Inc., New Jersey, NJ.

Matskevich, D., 2018, Preparing your business for the artificial intelligence revolution, viewed 21 August 2018, from https://www.forbes.com/sites/ forbestechcouncil/2018/07/12/preparing-your-business-for-the-artificialintelligence-revolution/\#ed5b6f27ac83.

Moore, V., 2009, 'Nano Entrepreneurship: Before nanotechnology can transform industries such as energy or biotech, its innovations have to be commercialized', Mechanical Engineering 131(4), 27-29. https://doi.org/10.1115/1.2009APR-2

Mutula, S.M. \& Wamukoya, J., 2007, Web-based information management: A cross disciplinary approach, Chandos Publishing, Oxford.

Nakamura, H. \& Zeira, J., 2018, Automation and unemployment: Help is on the way, viewed 21 August 2018, from https://voxeu.org/article/automation-andunemployment-help-way.

Ojasalo, J. \& Ojasalo, K., 2018a, 'Lean service innovation', Service Science 10(1), ii-iii, 1-109, C2. https://doi.org/10.1287/serv.2017.0194

Ojasalo, J. \& Ojasalo, K., 2018b, 'Service logic business model canvas', Journal of Research in Marketing and Entrepreneurship 20(1), 70-98. https://doi. org/10.1108/JRME-06-2016-0015

Osterwalder, A. \& Pigneur, Y., 2010, Business model generation, John Wiley \& Sons, Inc., New Jersey, NJ.

Perkin, N. \& Abraham, P., 2017, Building the agile business through digital transformation, Kogan Page Ltd, New York, NY.

Razak, A.A., Murray, P.A. \& Roberts, D., 2014, 'Open innovation in universities: The relationship between innovation and commercialisation', Knowledge and Process Management 21(4), 260-269. https://doi.org/10.1002/kpm.1444

Saunders, M., Lewis, P. \& Thornhill, A., 2009, Research methods for business graduates, 5th edn., Pearson Education Limited, Essex.

Saunders, M., Lewis, P. \& Thornhill, A., 2012, Research methods for business graduates, 6 th edn., Pearson Education Limited, Essex.

Schwab, K., 2016a, The fourth industrial revolution, World Economic Forum, Geneva.

Schwab, K., 2016b, The fourth industrial revolution: What it means, how to respond, viewed 5 April 2018, from https://www.weforum.org/agenda/2016/01/thefourth-industrial-revolution-what-it-means-and-how-to-respond/.

Schwab, K., 2018, The urgency of shaping the fourth industrial revolution, viewed 5 April 2018, from https://www.weforum.org/agenda/2018/01/the-urgency-ofshaping-the-fourth-industrial-revolution.

Schwertner, K., 2017, 'Digital transformation of business', Trakia Journal of Sciences 15(1), 388-393. https://doi.org/10.15547/tjs.2017.s.01.065

Skilton, M., 2017, The impact of artificial intelligence on business, Warwick Socia Sciences Policy Briefing, 4/2017, viewed 27 August 2018, from https://warwick. ac.uk/fac/soc.

Technopedia, 2018, Robotics, viewed 5 April 2018, from https://www.techopedia. com/definition/32836/robotics.

Watson, B., 2017, Design thinking as strategy, viewed from http://www.led. org.uk.

Zulu, S.F.C., Sebina, P.M., Grand, B. \& Mutula, S.M., 2012, 'Benchmarking Botswana's e-government initiatives with WSIS Principles: A review of progress and challenges', in K. Bwalya \& S. Zulu (eds.), Handbook of research on e-government in emerging economies: Adoption, e-participation, and legal frameworks, pp. 237-262, IGI Publishers, New York, NY. 